\title{
Denmark's success in reducing adolescent self-harm
}

\author{
William Gardner ${ }^{1}$
}

Received: 25 November 2019 / Accepted: 13 December 2019 / Published online: 1 February 2020

(c) Springer-Verlag GmbH Germany, part of Springer Nature 2020

Sarah Steeg and her co-authors report a welcome and surprising finding [1]. In a study of Danish health administrative records, they found that the incidence rate of self-harm among adolescents aged 10-19 years peaked in 2007 (at 25.1/10,000 Danish youths), and then decreased steadily to $13.8 / 10,000$ in 2016. This finding is welcome, because adolescent self-harm that requires medical attention is associated with future mortality, suicide, repeated self-harm, and increased health care costs [2].

This finding is surprising, because as the authors note, adolescents have been visiting hospitals for self-harm at increasing rates in many countries. I will focus on the contrast between Denmark and Canada, two prosperous Northern social democracies with extensive social safety nets, and high levels of personal happiness and social trust. However, in contrast to Denmark, in the Canadian province of Ontario, the rates of adolescents presenting at emergency departments (EDs) for self-harm fell 32\% from 2003 to 2009, while Danish levels of youth self-harm were rising, but then rose 135\% from 2009 to 2017, when Danish levels were falling [3]. Therefore, what does the Danish finding suggest about the causes of adolescent self-harm and about how Canadians might prevent it?

In looking for causes of the post-2007 increase in adolescent self-harm ED visits in Ontario, we noted that the Ontario economy went into recession in 2008 , about the same time that visit rates started to rise. However, the Danish economy also experienced a recession in 2008, and yet visits there fell. A second possible explanation for the increase in Ontario was the spread of smartphones. The iPhone launched in 2007, and many adolescents have

This comment refers to the article available at https://doi. org/10.1007/s00127-019-01794-8.

William Gardner

wgardner@cheo.on.ca

1 Children's Hospital of Eastern Ontario (CHEO) Senior Research Chair in Child and Adolescent Psychiatry, University of Ottawa, Ottawa, ON, Canada become increasingly immersed in social media. Twenge and her colleagues found that adolescents' self-reported mental health complaints and self-harm were associated with spending more time online and less time interacting in person [4]. However, rates of social media penetration in Denmark are similar to those in other countries [5]. It follows that either we were wrong in believing that exposure to economic adversity or social media was a factor in promoting selfharm among Ontario's youth, or there is some factor that Denmark has, and that Ontario does not have that protected Danish youth.

What might we learn from Denmark about reducing adolescent self-harm? First, adolescents frequently harm themselves by self-poisoning with analgesics. Steeg et al. note that Denmark stopped permitting adolescents to buy non-opioid analgesics over the counter in 2008. Similarly, the Danes limited over-the-counter analgesic pack sizes in 2011. These are, in my opinion, policies that Canada should adopt. However, rates of Danish adolescent self-harm by other methods also decreased after 2007, so there must also be other causes at work.

Second, Danes have better access to mental health care than many Canadians do. The accessibility of the mental health care system matters, because adolescent self-harm ED visits are associated with and, in some cases, are likely caused by mental health disorders [2]. Hegerl argues that effective detection and treatment of mental health disorders is a pillar of effective suicide prevention, and the same may be true of self-harm prevention [6]. Danes, however, have more access to mental health care than Canadians do, for several reasons. Danish publicly financed health insurance covers all mental health care and subsidizes outpatient prescription drugs [7]. Nordentoft and Erlangsen report that Denmark has increased access to outpatient mental health care by $66 \%$ since 2000 [8]. Canadian public health insurance does not cover outpatient mental health services by non-physicians and, for most Canadians, does not pay for outpatient medication prescriptions, which are critical elements of mental health care. Moreover, Denmark is geographically compact and densely populated, so that no one 
lives far from the metropolitan centres where mental health specialists tend to locate. In Ontario, mental health providers are concentrated in Toronto [9]. There are far fewer providers per capita in Ontario's extensive rural plains, let alone in northern villages than may be $1000 \mathrm{~km}$ from Toronto. As a result, many Ontarians (and other Canadians) live several hours away from the nearest mental health provider. Finally, good clinician-patient communication is crucial to effective mental health care. Likewise, almost all Danes speak Danish. Perhaps, one in five Canadians speak a language other than English in their homes, including French, Cantonese, Mandarin, several European languages, and more than 50 indigenous languages. Many of these families live in regions, where all or nearly all the mental health providers speak only English [10]. For all of these reasons, a Canadian is more likely to be unable to access effective mental health care than a Dane.

We can draw no definitive conclusions from the comparison of just two countries. Nevertheless, it is plausible that Canada could reduce the problem of adolescent selfharm by following Denmark's lead in two respects: first, by regulating pharmaceutical retailing to make it harder for adolescents to obtain large quantities of analgesics and second, and far more challenging, Canada should invest more thought and resources in improving the accessibility and quality of mental health care for all Canadians. Steeg et al.'s important article illustrates the need for more comparative studies of the social determinants of mental health disorders, suicide, and self-harm and the social systems for health care and prevention.

\section{Compliance with ethical standards}

Conflict of interest The author has no financial or personal interest that would constitute a conflict of interest with respect to the content of this manuscript.

\section{References}

1. Steeg S, Carr MJ, Mok PLH et al (2019) Temporal trends in incidence of hospital-treated self-harm among adolescents in Denmark: national register-based study. Soc Psychiatr Psychiatr Epidemiol. https://doi.org/10.1007/s00127-019-01794-8

2. Gardner W, Pajer K, Cloutier P et al (2019) Health outcomes associated with emergency department visits by adolescents for self-harm: a propensity-matched cohort study. CMAJ 191:E1207E1216. https://doi.org/10.1503/cmaj.190188

3. Gardner W, Pajer K, Cloutier P et al (2019) Changing rates of self-harm and mental disorders by sex in youths presenting to ontario emergency departments: repeated cross-sectional study. Can J Psychiatr. https://doi.org/10.1177/0706743719854070

4. Twenge J, Joiner T, Rogers M, Martin G (2018) Increases in depressive symptoms, suicide-related outcomes, and suicide rates among US adolescents after 2010 and links to increased new media screen time. Clin Psychol Sci 6:3-17

5. Clement J (2019) Active social network penetration in selected countries as of January 2019. Hamburg, Germany

6. Hegerl U (2016) Prevention of suicidal behavior. Dialogues Clin Neurosci 18:183-190

7. Vrangbaek K (2019) The Danish health care system. The Commonwealth Fund, New York

8. Nordentoft M, Erlangsen A (2019) Suicide—turning the tide. Science 365:725. https://doi.org/10.1126/science.aaz1568

9. Kurdyak P, Stukel TA, Goldbloom D et al (2014) Universal coverage without universal access: a study of psychiatrist supply and practice patterns in Ontario. Open Med 8:e87-e99

10. de Moissac D, Bowen S (2017) Impact of language barriers on access to healthcare for official language minority Francophones in Canada. Healthc Manag Forum 30:207-212. https://doi. org/10.1177/0840470417706378 